\title{
The Challenge of Linking Pest and Crop Models
}

\author{
M. J. Kropff, ${ }^{a, b, c}$ P. S. Teng ${ }^{a} \&$ R. Rabbinge ${ }^{c}$ \\ "The International Rice Research Institute, PO Box 933, 1099 Manila, Philippines \\ ${ }^{b}$ DLO-Research Institute for Agrobiology and Soil Fertility (AB-DLO), \\ PO Box 14, 6700 AA Wageningen, The Netherlands \\ 'Department of Theoretical Production Ecology, Agricultural University, \\ Bornsesteeg 47, 6708 PD Wageningen, The Netherlands
}

\begin{abstract}
Developing integrated pest management systems requires detailed quantitative knowledge of the interactions between the crop and its pests (insects, diseases and weeds) to identify intervention points and to predict effects through damage relationships or yield loss functions. Because of the complexity of such systems, models at different levels of detail are needed to provide insight into the mechanisms of crop-pest interactions. These insights may form the basis prediction and decision support systems.

Several approaches have been developed to link pest models with crop models. Several coupling points for pest-crop models were identified for different pest-crop combinations. These were modeled on the basis of experimental research on the quantification of the physiological damage mechanisms. Examples are given of the use of the models that simulate the impact of pests on crops as an important research tool. Recently, approaches to simulate multiple pest damage have been developed and evaluated. Special attention is given to the use of such models to understand and predict the effects of weeds on crops.

The approach of linking pest and crop models provides a tool with which to explore the dynamics of the interactions and optimize pest management strategies.
\end{abstract}

\section{INTRODUCTION}

Diseases, insects and weeds, in this paper collectively referred to as 'pests', have strongly affected crops at low and high production levels since agricultural activities began. In recent decades, concepts in crop protection have changed from the exclusion or destruction of pests to 
pest management. Serious problems with pesticides, such as the rapid development of pest resistance, environmental effects of pesticides and increasing costs, have triggered the development of new approaches and techniques in pest management based on improved knowledge of pest dynamics and their natural enemies and the interaction between the pest and the crop. Quantitative models have been useful in integrating the detailed knowledge of the underlying processes. Recent attempts to link pest and crop models have increased our understanding of the complex pest-crop systems, especially in studies where modeling was combined with detailed experimental work (Bastiaans, 1993).

An improved understanding of the system may help to identify new control techniques by indicating intervention points and can be useful in decision-making in pest management (Rabbinge et al., 1989; Boote et al., 1993; Pinnschmidt et al., 1994). A distinction must be made between tactical decisions, with a short time-frame for decision-making (e.g. when and if spraying a particular pesticide in a specific field situation is economical), and strategic decisions with a longer timestep for decisionmaking (e.g. what weed control strategy must be followed to avoid weed problems in future crops, or what rotation prevents the development of pests and diseases most effectively). Decision support systems, in whatever form, should produce decision rules for intervening in a situation either directly or indirectly. Central to the decision-making process in pest management is information on the effect that a particular pest population has on the physical and economic output of the crop. This effect has to be premised on crop development stage, the prevailing environment, and the crop genotype's yield potential and ability to compensate for pest injury. Rapid advancements in microcomputer hardware and software, and their improved availability, helped advance the decision-making process significantly, building on research to generate the social, economic and biological knowledge needed to improve pest management decision-making (Teng \& Rouse, 1984; Teng \& Savary, 1992).

Decision support systems range from simple decision rules to complex multiple criteria optimization software. In its simplest form, a decision support tool could be a threshold pest infestation level calculated from empirical relations based on field data. Empirical models and thresholds have been developed for many pests in recent decades (Zadoks, 1985). Successful decision support systems have been developed based on these relationships (Rabbinge \& Rijsdijk, 1984; Rijsdijk et al., 1989).

In the 1980s, efforts were started to link more complex pest and crop models (Rabbinge, 1983; Boote et al., 1983; Rouse, 1988; Teng, 1988; Rabbinge et al., 1989). This enabled the development of interactive computer systems that use simulation models, data bases, and decision 
algorithms, in an integrated way, e.g. the Decision Support System for Agrotechnology Transfer (DSSAT), developed by the International Benchmark Sites Network for Agrotechnology Transfer (IBSNAT) project of a consortium of US universities (Jones, 1993).

In this paper, progress with respect to linking pest and crop models will be discussed. First, different approaches for modeling pest damage will be discussed, followed by a more detailed discussion of ecophysiological crop models, models for pest dynamics and linking points between these models. A detailed example of linking crop-weed models is given with potential applications. This review considers modeling efforts that aim at understanding and insight, thus paving the way for decision models to be used in pest management. It focuses mainly on operational and tactical decision-making.

\section{MODELING PEST DAMAGE}

Models at different levels of detail have been developed to quantify pest damage ranging from empirical functions to mechanistic simulation models. As indicated in the introduction, empirical approaches are often used to quantify economic threshold levels in decision support systems for pest management. These empirical damage functions are generally derived by regression analysis relating a measure of pest severity at a given crop stage to yield loss. These functions have been useful because of their relative simplicity, but they ignore the dynamics of crop-pest interactions. Thus, their value is generally limited to the specific conditions at which the measurements were taken. This was shown by Kropff et al. (1984) who demonstrated the large differences in the relation between Echinochloa crus-galli density and maize yield loss in two different years at the same site.

More realistic approaches use measures that integrate the severity or effect of a pest throughout the growing season. An example is the areaunder-disease-progress-curve (AUDPC), which measures the cumulative diseased host fraction, or the healthy-area-absorption (HAA), which measures the radiation intercepted by healthy tissue (Pinnschmidt et al., 1994). The advantage of these measures is that they integrate the dynamics of a pest over the season. However, much information on the dynamic interactions in these approaches is not explicitly included, which limits the potential for extrapolation. Also, the approach does not add to a mechanistic understanding of the damage mechanisms.

Substantial progress has been made in the past decade to link pest effects at the physiological level to dynamic ecophysiological crop 
models. Potential damage mechanisms have been identified that link pest effects to crop growth and development at the physiological level (Boote et al., 1983; Rabbinge, 1983; Rabbinge et al., 1989). The damage mechanism is introduced by a quantitative equation that links a pest variable (i.e. population number, proportion injured, and amount of consumed plant tissue) to a crop variable (i.e. leaf area and photosynthetic rate) (Rabbinge et al., 1989). Several crop models have been used to link effects of pests: for rice, MACROS, ORYZAl, CERES-Rice; for peanuts, PEANUTGRO; for soybean, SOYGRO; and for wheat, MACROS and SUCROS (Teng et al., 1995a). In the following sections the relevant characteristics of crop models are discussed first, followed by pest models and the linking points.

\section{CROP MODELS AVAILABLE FOR LINKING PEST EFFECTS}

Of the ecophysiological crop models, two types can be distinguished based on the level of detail in which they simulate dry matter accumulation. The first type involves models that simulate daily dry matter production based on leaf photosynthesis and respiration, using detailed routines for light absorption at different heights in the canopy and for different times during the day. Examples are the SUCROS models, generic models that were parameterized for many crops like wheat, potato and maize (Spitters et al., 1989); MACROS models (Penning de Vries et al., 1989); the ORYZA models (rice) that were derived from SUCROS and MACROS by Kropff et al. (1994); and the GRO models for crops like soybean, peanut and other leguminous crops (Jones et al., 1989). These models use a detailed calculation procedure for the rates of daily dry matter production described by Spitters et al. (1989). The total daily rate of canopy $\mathrm{CO}_{2}$ assimilation is calculated from the daily incoming radiation, temperature and the leaf area index. The submodel contains a set of subroutines that calculate the daily rate of canopy $\mathrm{CO}_{2}$ assimilation by integrating instantaneous rates of leaf $\mathrm{CO}_{2}$ assimilation. The photosynthesis profile in the canopy is obtained on the basis of the light profile in the canopy and the photosynthesis characteristics of single leaves. Integration over the leaf area index of the canopy and over the day gives the daily $\mathrm{CO}_{2}$ assimilation rate. The net daily growth rate in kilograms of dry matter per hectare per day is obtained after subtracting the respiration requirements. Effects of pests and diseases on physiological processes at the organ level can be introduced in these models (e.g. leaf photosynthesis, leaf respiration).

The second type involves models that use a radiation use efficiency 
(grams of dry matter per joule of radiation absorbed) approach to estimate dry matter accumulation directly from the daily absorbed radiation by the canopy, i.e. the CERES models. In CERES-Rice for example, the growth submodel simulates plant mass accumulation, expansion growth, assimilate partitioning and senescence. Potential mass accumulation is dependent on absorption of photosynthetically active radiation, the radiation use efficiency (RUE), leaf area index (LAI), and light extinction coefficient as affected by row spacing (Singh et al., 1993). Effects of pests on growth processes must be introduced as a reduction factor for the RUE in these models.

The two types of models can be complementary. The detailed leaf photosynthesis based approach can be used to model the impact of measured information on the effect of a particular pest, disease, or excretion of a pest like honeydew, on leaf photosynthesis and respiration on canopy photosynthesis. Such effects are relatively easy to measure. The effect of the actual distribution of the pest in the crop canopy can be analysed as well. This is important because diseases often affect photosynthesis at high radiation levels, whereas the severity is often highest at lower levels in the canopy where radiation levels are low. The detailed approach simulates the RUE for the canopy based on the underlying processes. An example was given by Bastiaans \& Kropff (1993) for the effect of leaf blast on rice.

In the other approach, where the RUE is an input parameter of the model, field-scale measurements are needed to calculate the RUE at different pest levels. The effect of the dynamics cannot be directly studied because the dynamics are integrated in the approach. However, the effect of a specific pest on the RUE could be simulated by the detailed model, summarized and used as input in a RUE-type model.

Other features like morphological development (leaf-area development, tillering, etc.), phenological development, water stress effects, nitrogen effects and effects of other factors are simulated in varying detail (if accounted for) by the different models. Some models only simulate potential yield- and/or water-limited yields, whereas others simulate $\mathrm{N}$ effects as well.

\section{QUANTIFICATION OF PEST DYNAMICS}

Simulation approaches for pest population dynamics were reviewed by Rabbinge \& Carter (1983) and Teng (1985) for diseases, Rabbinge et al. (1989) and Teng et al. (1995b) for insects, and Spitters (1989) for weeds. A detailed description of how to construct simulation models of pest 
population dynamics is given by Rabbinge et al. (1989). Simple pest population dynamics models that have been used intensively are exponential or logistic growth curves. Such models can be quite complicated, especially when different generations of a pest are modeled. These models include the effects of driving variables, such as weather, on various aspects and stages of the pests' life-cycles. Two basic processes form the core of these models: growth (e.g. newly hatched insect pest individuals, new infections, lesion growth, etc.) and removal (e.g. death of insect pest individuals, senesced lesions, etc.) of a pest population. Many equations are generally added to model-specific aspects and sub-processes as affected by driving variables. For example, the population can be split into classes representing lesions or larvae of different age. Goudriaan and Van Roermund (1989) described the so-called BOXCAR train procedure that facilitates the distinction of age classes in a population. For each age class, processes can be calculated separately and at pre-defined moments, individuals change classes. Parameters can be functions of environmental, host and pathogen factors, and for diseases, growth might be subdivided into new infections and growth of existing lesions. Other important subprocesses to be modeled are oviposition, hatching, survival, search behavior, migration for insect pests and sporulation, spore dispersal, spore deposition, and latency for diseases. When the pest and crop models are not directly linked, the pest levels that are computed by the pest model can be stored as progress curves as input for the crop model. Most studies on crop-pest interactions quantify the pest population by using empirical approaches or observations (Pinnschmidt et al., 1994). Studies on crop-weed interactions are an exception because weed growth can be modeled using well-developed crop models (Kropff \& Van Laar, 1993).

\section{DAMAGE MECHANISMS: LINKING PEST EFFECTS TO CROP MODELS}

The linking procedure for pest-crop modeling has been discussed in detail by Boote et al. (1983, 1993), Loomis and Adams (1983), Rouse (1988), Teng and Johnson (1988), Rabbinge et al. (1989), and Kropff and Van Laar (1993). Coupling points are located at the level of resource capture (light, water, nutrients), at the process level (photosynthesis, respiration, translocation) or at the state variable level (consumption of assimilates, biomass, leaf area). Several generic damage mechanisms have been identified by Rabbinge (1983); Boote et al. (1983) and Rabbinge et al. (1989). Different categories of damage mechanisms can be distinguished (Rabbinge et al., 1994): competition for resources, plant killing, 
reduction of assimilation rate, effects on respiration, tissue necrosis and interception of light, tissue consumption, assimilate consumption, hampering of water uptake, induction of hormonal effects on stomatal regulation and deformations. Some examples of the most widely used categories of pests, with respect to their damage mechanism and their relation to crop growth are given in Table 1, which is modified from Rabbinge and Bastiaans (1989). In Fig. 1 the linking points in a SUCROS type model are indicated (Rabbinge et al., 1989).

The main effect of weeds is the capture of resources that are required for crop growth. For example, when weeds compete with the crop for light, the weeds capture light in the canopy, making it unavailable for crop assimilation. Most authors indicate this with the category lightstealers. However, because weeds also capture resources like water and nutrients, the category resource-stealers is more complete. Several models were developed in the 1980s based on mechanistic approaches to interplant competition (Kropff \& Van Laar, 1993). In the early 1980s, Spitters and colleagues started developing ecophysiological models for interplant competition, based on ecophysiological models for monoculture crops (Spitters \& Aerts, 1983; Kropff et al., 1984). They focused on crop-weed competition for light and water. These models were based on the

TABLE 1

Damage Mechanisms of Pests on Crops (Modified from Rabbinge \& Bastiaans, 1989)

\begin{tabular}{lll}
\hline Categories of pests & \multicolumn{1}{c}{ Growth-determining aspects } & \multicolumn{1}{c}{ Examples } \\
\hline Resource stealers & - covering leaf area & - fungi that cover leaves \\
& $\begin{array}{l}\text { - capture of light, water or } \\
\text { nutrients }\end{array}$ & - weeds \\
Stand reducers & - reduction plant density & - fungi \\
& - compensation mechanisms & - insects (e.g. stemborer in \\
& & rice) \\
Assimilation-rate & - effect on photosynthetic reactions & \\
reducers & - position of affected leaves in & - powdery mildew \\
& canopy & - beet yellow virus \\
Assimilate sappers & - carbohydrate consumption & \\
& - excretion harmful products & \\
Tissue consumers & - tissue consumption rate & - mites \\
& &
\end{tabular}




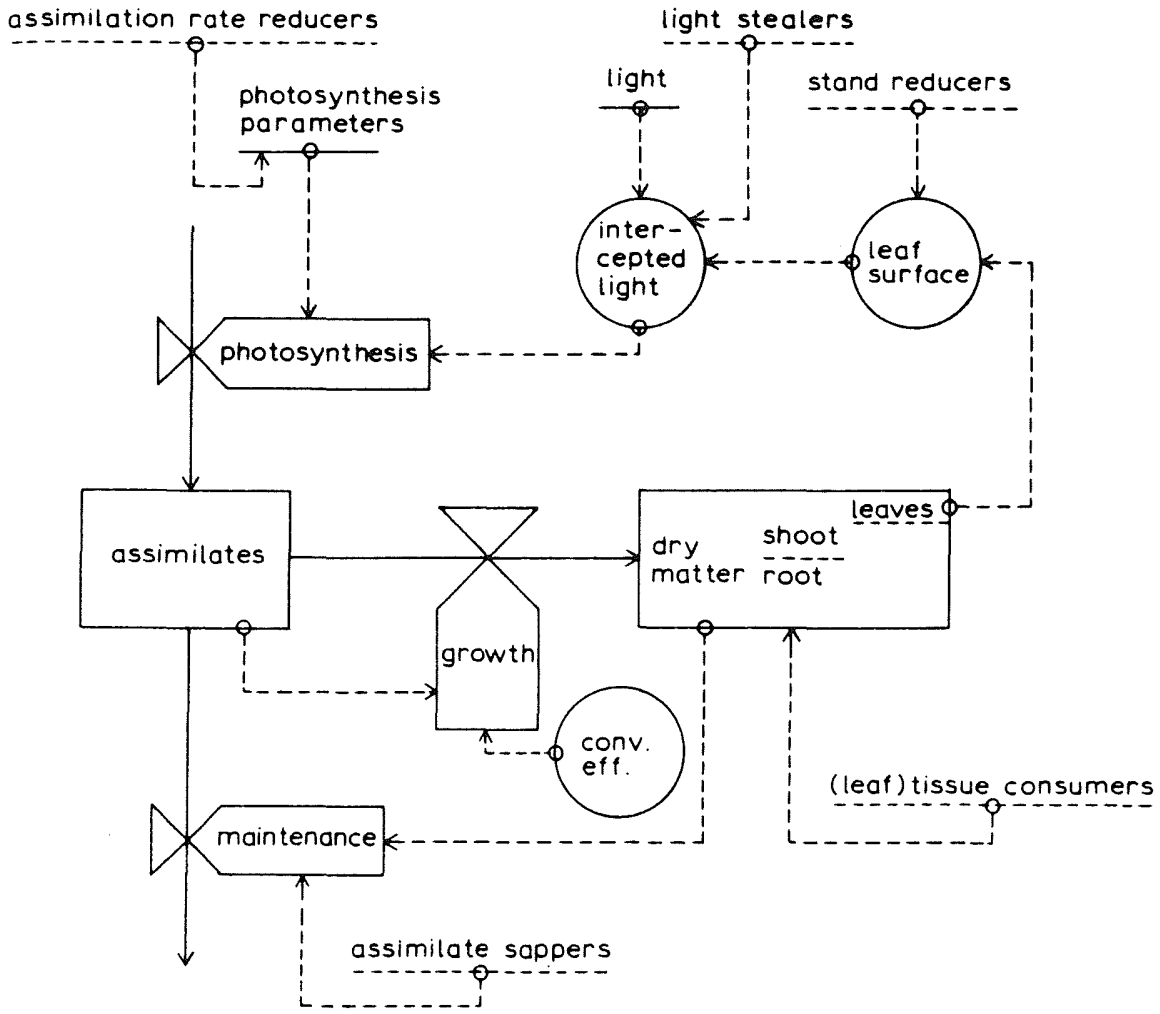

Fig. 1. Relational diagram of the model SUCROS indicating the generic linking points for pests (Rabbinge et al., 1989).

assumption that competition is a dynamic process that can be understood from the distribution of the limiting resources between the competing neighboring plants and the efficiency with which each plant uses the resources captured. So, weeds and crops are interacting by changing the environment and resource availability. Similar approaches to quantify crop-weed interactions were developed by Graf et al. (1990b) and Wilkerson et al. (1990). The way in which competition for light is modeled in the model INTERCOM (Kropff \& Van Laar, 1993) is schematically represented in Fig. 2. For each species, a crop growth model is operated. The models are linked in that the calculation of light capture by the competing species is simulated explicitly by distributing the canopy in a large number of thin leaf layers and calculating light absorption of the competing species in each layer. The model can be used for multiple species if sufficient computing power is available.

Stand reducers are insects or diseases that kill plants in the canopy, e.g. stemborer in rice (Rubia \& Penning de Vries, 1990). The severity of 


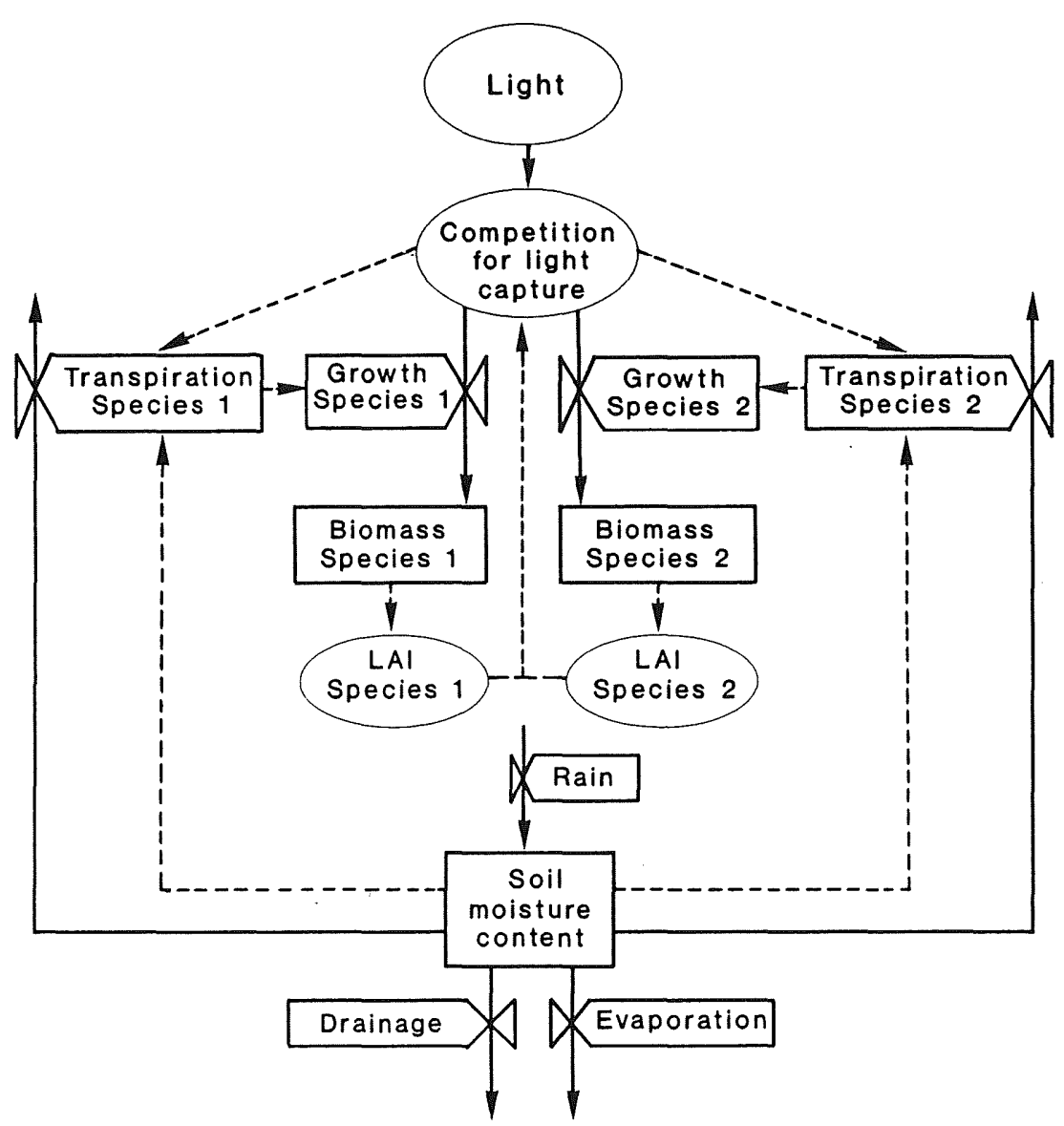

Fig. 2. General structure of the model INTERCOM for crop-weed interactions with coupling points (Kropff \& Van Laar, 1993).

damage the pests cause depends upon the compensation mechanisms available to the crop. Rice and other cereals can compensate such effects when they occur in the tillering stage of the crop. Other crops like beets or maize compensate for open spots in the canopy less effectively.

Assimilation rate reducers affect the photosynthetic capacity of green tissue even if the green tissue is not consumed. Many pathogens (fungi, bacteria, viruses) belong to this category. Bastiaans (1991) introduced the virtual lesion concept because he found that the reduction of photosynthesis by leaf blast in rice was three times as high as expected from the proportion of damaged leaf area. Apparently, photosynthesis in the green leaf tissue around the lesion is strongly affected as well. Other examples of assimilation rate reducers in rice are bacterial leaf blight 
(Reddy et al., 1991), and sheath blight (Singh \& Das, 1991; Elings, A., pers. comm.). Some pests may have other major damage mechanisms like the consumption of tissue, but affect adjacent tissue through metabolites.

Assimilation sappers are pests that remove carbohydrates from the plant. These can be sucking insects like aphids (Rossing, 1993), nematodes and pathogens. To link these pests to crop models, predictions of consumption rates per individual or severity unit are required.

Tissue consumers may feed on different plant parts like roots, leaves, stems, storage organs, etc. Most visible are leaf consumers that reduce the capacity of the crop to capture light and to photosynthesize. The main parameters are the type of tissue, the consumption rate and the timing. Examples for rice pests are leaf blast (necrosis) and leaf-folders.

Boote et al. (1993) also distinguished the category of leaf senescence accelerators and turgor reducers. The first category can also be seen as leaf consumers because they reduce leaf area and, thereby, light interception. These categories have to be seen as a broad framework. Defining the category for a given pest is difficult because some pests affect the crop in several ways.

The simulation of pest effects with pest-coupled crop models requires quantitative data on the mechanisms of pest damage. For example, daily leaf consumption rates as established for leaf-folders by Heong (1990) or the functional relationship between leaf blast severity and leaf photosynthesis found by Bastiaans (1991) can be used for formalizing and parameterizing pest damage effects in crop simulations. Plant age, larval age and development stage, varietal resistance and temperature affect feeding activities (Kim \& Kim, 1986; Cheng, 1987; Heong, 1990) and must be appropriately considered. Where direct observations of damage mechanisms are difficult, researchers have used indirect methods, like honeydew production, to estimate the assimilate consumption of brown plant hoppers (Sogawa, 1970; Kim \& Kim, 1986).

\section{COUPLED PEST-CROP MODELS}

The most advanced approach in linking pest-crop models would be to run a pest population model in interaction with the crop model. In many studies the pest model was run first to calculate pest dynamics in a summarized form (e.g. AUDPC). In most studies, however, quantitative information on pest dynamics was derived from observed data, and predicting pest population dynamics is complex because of the many feedback processes. A general review of examples from the IBSNAT network was given by Boote et al. (1993) for insects and diseases in soybean, 
peanut and rice, and by Pinnschmidt et al. (1994) and Teng et al. (1995b) for rice. A review of examples from the Wageningen modeling group for temperate crops was given by Rabbinge et al. $(1993,1994)$. Here we will limit our examples to rice. Most of the work on rice was conducted using either MACROS (Penning De Vries et al., 1989), ORYZAl (Kropff et al., 1994) or CERES-Rice (Alocilja \& Ritchie, 1988). Pinnschmidt et al. (1994) surveyed the literature and found that in most studies empirical pest levels were introduced into the crop simulation. In a few studies, pest development was driven by crop variables and vice versa (Benigno et al., 1988; Graf et al., 1990a; Kropff \& Van Laar, 1993). Generally, single pest species were simulated. However, several attempts were made to incorporate the effects of multiple pest populations on simulated crop yield (Pinnschmidt et al., 1994). These typically involved incorporating interactive effects of a limited number of damage types such as reduction of photosynthesis, leaf feeding, removing assimilates, detillering, respiration increase, and competition for light, nitrogen, and water. In many cases, pest damage mechanisms were parameterized using expert guesses, due to a lack of quantitative data.

In CERES-Rice, 20 generic coupling points were identified (Pinnschmidt et al., 1994): leaf, root, stem, panicle and grain consumption, leaf shading, photosynthesis reduction, assimilate consumption, respiration increase, phloem blockage/translocation reduction, growth rate reduction of leaf, root, stem and grain, light competition, leaf senescence acceleration, xylem blockage, altered transpiration, stand reduction, and blockage of leaf and stem reserves. The coupling points corresponded to damage sites incurred by the most important rice pests. To implement the equations associated with each coupling point and damage mechanism, a structure had to be developed to define pest damage and apply pest damage to coupling points in the crop model. A pest module was developed to read pest data into the model and compute the effects of pest damage on coupling points (Pinnschmidt et al., 1994). The damage relations were quantified for the most important rice pests, sometimes based on experimental data, but sometimes also based on expert guesses. When simulating specific examples from the literature, an excellent fit was obtained between simulated and observed yield losses for simple damage such as that caused by detillering as well as complex damage such as that caused by sheath blight (Pinnschmidt et al., 1994).

In the Systems Analysis and Simulation for Rice Production (SARP) project, scientists in Asian national research systems collaborated with IRRI and the Wageningen modeling group to develop models for the effects of bacterial leaf blight and stemborer (BLIGHT and SBORER), based on the ORYZA1 model. The models are documented in detail by 


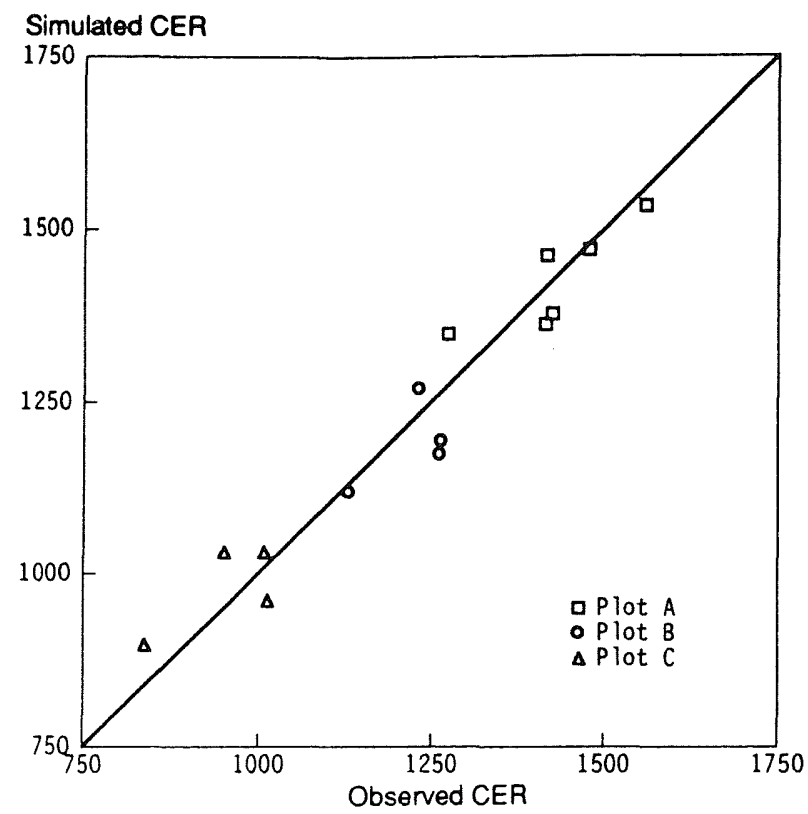

Fig. 3. Comparison of observed and simulated canopy gas exchange rate (CER; $10^{-6} \mathrm{~g}$ $\mathrm{CO}_{2} \mathrm{~m}^{-2} \mathrm{~s}^{-1}$ ). Plot A was the control plot, plot B was infected with blast at 27 days after transplanting, and plot $\mathrm{C}$ at 20 and 34 days after transplanting (Bastiaans \& Kropff, 1993).

Elings and Rubia (1994). The focus has been on understanding the mechanisms and quantifying the coupling points.

\section{EXAMPLES OF USING COUPLED PEST-CROP MODELS FOR RICE}

\section{Analysis of leaf blast effects in rice}

A detailed quantitative study of the effects of leaf blast in rice, on the basis of basic physiological processes, was conducted by Bastiaans (1993). Based on the analysis of effects on leaf photosynthesis, the effect on canopy gas exchange rate was predicted and compared with real measurements in the field. The analysis showed that the effect of leaf blast on canopy photosynthesis was through the effect of the lesions on photosynthetic rates and the shading effect of the lesions (Bastiaans \& Kropff, 1993). A comparison of observed and predicted canopy photosynthesis at different levels of blast infection is given in Fig. 3. This shows that on the basis of the damage relationship for leaf photosynthesis and the mechanistic canopy photosynthesis model, the effects at the canopy level (with measured LAI and severity as input) can be quantita- 


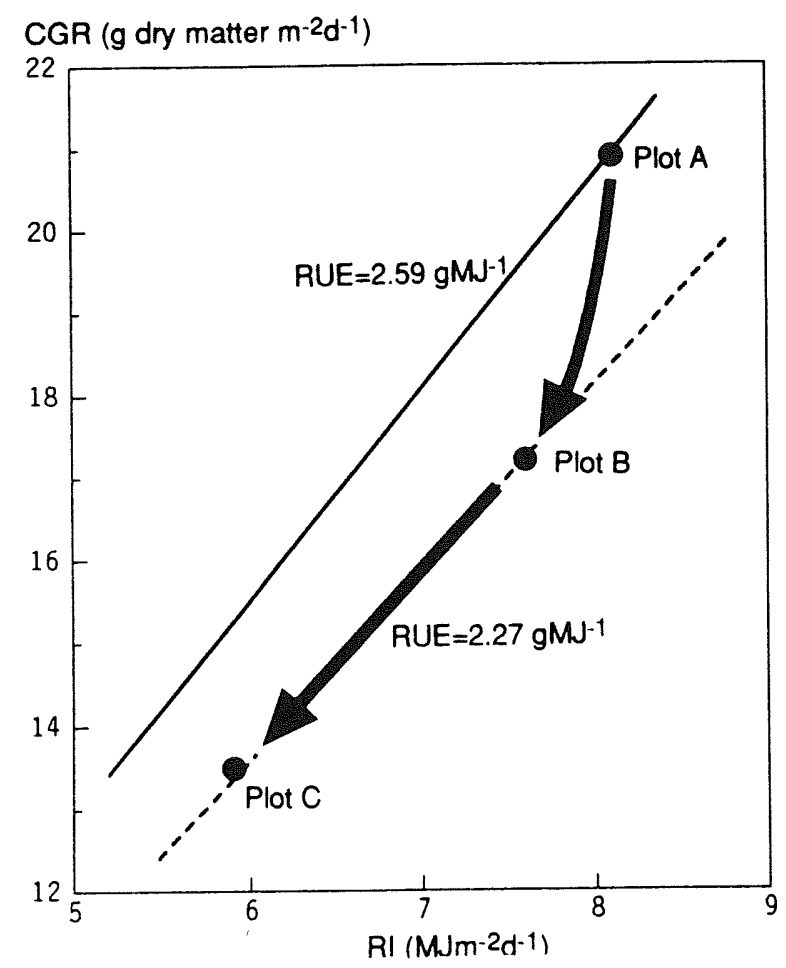

Fig. 4. Simulated rice crop growth rate (CER; $10^{-6} \mathrm{~g}^{\mathrm{CO}} \mathrm{CO}_{2} \mathrm{~m}^{-2} \mathrm{~s}^{-1}$ ), radiation interception by green leaves ( $\mathrm{RI} ; \mathrm{MJ} \mathrm{m}^{-2} \mathrm{day}^{-1}$ ) and radiation use efficiency (RUE; g dry matter $\mathrm{MJ}^{-1}$ ) based on data from three experimental plots (see caption to Fig. 3). The arrows indicate the hypothetical time course of effects of blast on the crop growth rate (Bastiaans \& Kropff, 1993).

tively understood. Sensitivity analysis showed the importance of the vertical distribution of the disease severity in the canopy (Bastiaans \& Kropff, 1993). The model was subsequently used to predict the RUE for the crops at different levels of infection. Figure 4 shows that moving from a healthy crop (plot A) to a one-time infected crop (Plot B) mainly results in a decrease in RUE. However, if the crop is more heavily infested (inoculated twice), the dead leaves, accelerated senescence and shading effects reduce the intercepted radiation by the crop. This analysis suggested that, in the long run, yield is more affected by accelerated senescence than by the effects on leaf photosynthesis (Bastiaans \& Kropff, 1993).

The CERES-Rice model was used to determine the relation between the onset time for blast infection, the maximum severity level of the disease and yield loss in rice by Teng et al. (1995b). Generic disease progress curves were developed, characterized by the onset time and the maximum 


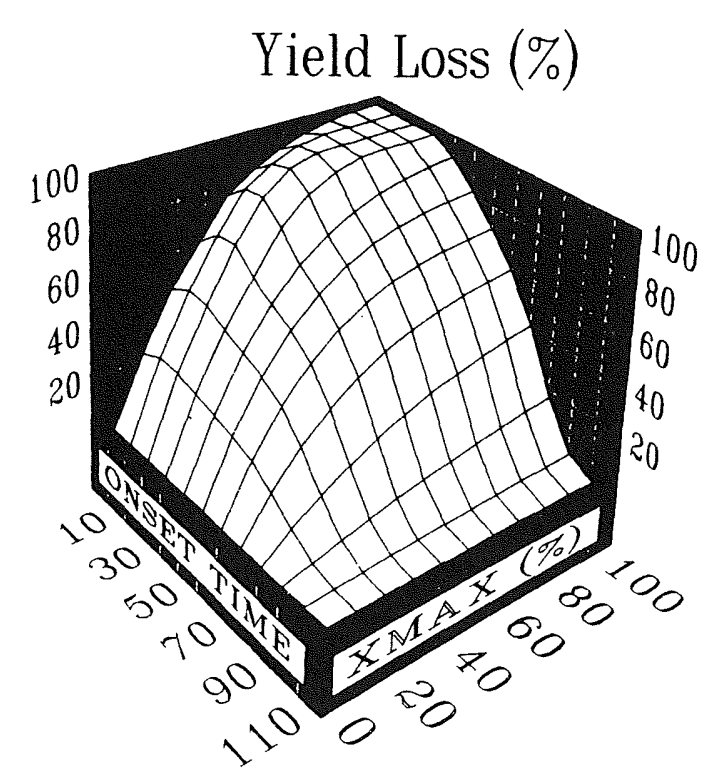

Fig. 5. Simulated yield loss due to leaf blast in rice as affected by onset time and the maximum severity level of the disease (Teng \& Pinnschmidt, in Boote et al.,1993).

level. The results are illustrated in Fig. 5. Luo et al. (1995) coupled the CERES-Rice model to the model BLASTSIM (Calvero \& Teng, 1992), which simulates the population dynamics of the disease. Direct interactions between the models were included. The model was used to simulate the potential impact of climatic change on rice yield, showing that an increased temperature will increase blast severity and risk in temperate climates, but will reduce effects in tropical climates (Teng et al., 1995a).

\section{Modeling crop-weed competition and applications in weed management}

Ecophysiological models for interplant competition for light, water and nutrient resources have been developed in the past decade by linking plant growth models for crop and weed species (Spitters, 1989; Kropff \& Van Laar, 1993). These models are based on the principle that competition is a dynamic process that can be understood from the distribution of growth-determining (light) or growth-limiting (water and nutrients) resources to the competing species and the efficiency with which each species uses the available resources. Ecophysiological models that simulate these processes provide insight into competition effects observed in field experiments and may help in seeking ways to manipulate competitive relations, such as those between crop and weeds, by determining the most important factors in crop-weed competition. 
The ecophysiological models consist of coupled crop growth models equal to the number of competing species. The model INTERCOM is the most widely tested to date (Kropff \& Van Laar, 1993). Experimentspecific input requirements of the ecophysiological model include geographical latitude, standard daily weather data, soil physical properties, dates of crop and weed emergence, and crop and weed density. A detailed description of the ecophysiological simulation model is given by Kropff and Van Laar (1993). Under favorable growth conditions, light is the main factor determining the growth rate of the crop and its associated weeds. From the LAI of the species, the vertical distribution of their leaf area and light extinction properties, the light profile within the canopy is calculated. Based on the species' characteristics for the photosynthetic light response of single leaves, the vertical photosynthesis profile of each species in the mixed canopy is obtained. Integration over the height of the canopy and over the day gives the daily assimilation rate for each species. After subtracting the respiration requirements for maintenance, the net daily growth rate in kilograms of dry matter per hectare per day is obtained using a conversion factor for the transformation of carbohydrates into structural dry matter. The dry matter produced is partitioned among various plant organs, using partitioning coefficients that are introduced as a function of the phenological development stage of the species. The phenological development rate is tracked in the model as a function of ambient daily average temperature. When the canopy is not closed, leaf area increment is calculated from daily average temperature, since leaf expansion is sink-limited. When the canopy closes, the increase in leaf area is obtained from the increase in leaf weight using specific leaf area (SLA $\mathrm{m}^{2}$ leaf $/ \mathrm{kg}$ leaf) because leaf expansion is source-limited at this stage. Integrating daily growth rates of the organs and leaf area results in the time course of LAI and dry weight during the growing season. Height growth rate is calculated as a function of temperature.

Nutrient competition has not yet been included in the model because nutrients were always in ample supply in the validation experiments. For situations where $\mathrm{N}$ is limiting, an extended version of the model can be used according to the principles described by Kropff and Van Laar (1993). The model INTERCOM was tested with data from competition experiments with the following combinations: maize (Sinapis arvensis L.), maize (Echinochloa crus-galli L.) and sugarbeet (Chenopodium album, L.) in the Netherlands; tomato (Amaranthus retroflexus L.) and tomato (Solanum americana) in Canada, and rice (Echinochloa crus-galli) in the Philippines (Kropff \& Van Laar, 1993). The model INTERCOM was evaluated in most detail using a wide range of data sets on competition 

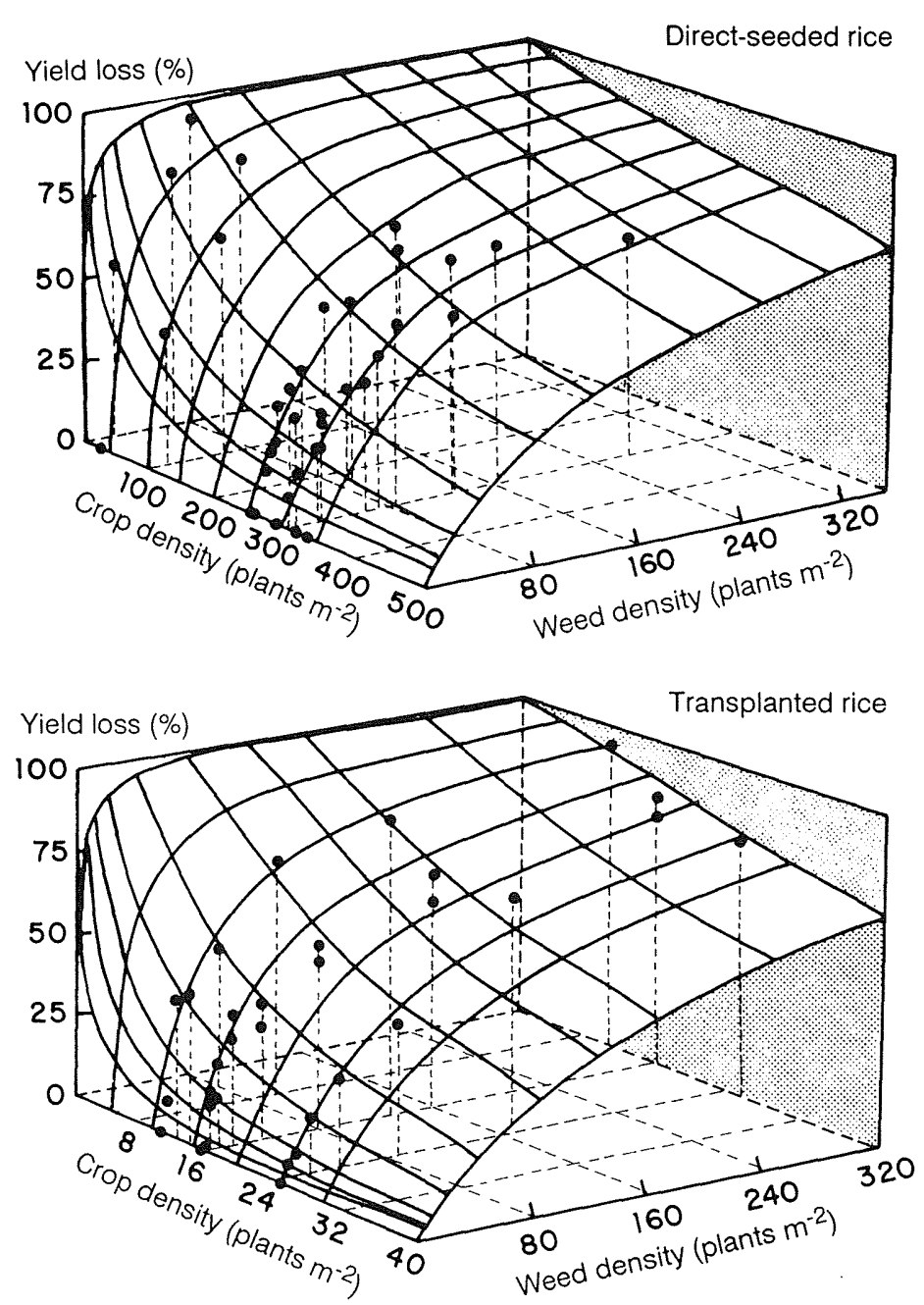

Fig. 6. Yield loss as a function of rice and weed (Echinochloa crus-galli) density as simulated by the model INTERCOM (drawn response surfaces) and observed (1) for transplanted rice (Kropff \& Van Laar, 1993).

between Echinochloa species and transplanted or direct-seeded rice (Kropff \& Van Laar, 1993). The yield loss response surface was accurately predicted by the model over this wide range of competition situations (Fig. 6). This means that the differences in yield loss between the experiments can be explained by the ecophysiological model based on crop density, weed density and the period between crop and weed emergence, and establishment method of rice. Similar results were found for other crop weed combinations (Kropff et al., 1992; Weaver et al., 1992; Kropff \& Van Laar, 1993). 
Several types of applications of the model were suggested by Kropff and Van Laar (1993). The first application was to help understand what the major factors were that determine variation in yield loss between situations. An important conclusion was that the time of weed emergence relative to the crop was a major factor determining yield loss differences in the experiments with sugarbeet. The simulation model was then used to determine, for weed infestation, if using measures other than just density would allow a better prediction. The modeling study indicated that the relative leaf cover of the weeds shortly after crop emergence would be a better measure because it accounts for the relative starting position of the weeds (Kropff, 1988). Kropff and Spitters (1991) derived a new empirical model based on this conclusion and found that the approach indeed enabled a more accurate prediction of yield loss. Another example of an application is using the model to analyse if another plant type for rice would more effectively suppress weeds. The theoretical analysis initiated experimental and breeding work at IRRI to develop such plant types.

All these applications focus on developing improved weed management systems that require thorough quantitative insight into the behavior of weeds in agroecosystems. To improve weed management systems, two strategies could be formulated: (1) reduce weed effects through adapted crop management, and (2) improve decision-making by predicting yield loss due to weeds early in the growing season. With respect to the first option, the application in breeding to design plant types with enhanced competitiveness comes in mind. Since weed problems obviously cannot be solved by adapting general management practices alone, decisionmaking on applying specific weed control measures is needed. The complex ecophysiological models require too many inputs to be useful for linking field observations to yield loss in agricultural practice, like the dates of crop and weed emergence (which is practically impossible when weeds emerge in separate flushes) and weed densities. Simple approaches such as the relative leaf-area yield loss model (Kropff \& Spitters, 1991), which allow reasonably accurate prediction of the effect on final yield, can serve as a tool if simple observation methods of relative leaf cover are developed.

\section{THE FUTURE OF LINKING PEST AND CROP MODELS}

Different types of decision tools in pest management can be distinguished: knowledge (e.g. threshold), physical (e.g. seed), communication (e.g. radio, visits) and policy tools (e.g. laws) (Teng, 1994). The use of these tools requires information on pest status, crop status, the anticipated effect of pest status on crop productivity, and the effect of various 
management options. The possibility of linking pest and crop models opens new options to improve one of the most complex requirements for decision-making in pest management: quantifying the anticipated effects of the pest. Because predicting pest population dynamics is less accurate than quantifying the damage or crop production because of the complexity and nature of the process (Rossing, 1993), other ways to quantify pest populations (e.g. based on measurements) must sometimes be used in studies, depending on the objectives of the study. However, the models can be useful in analysing risk and uncertainty, which is an essential element in decision-making for pest management.

Introducing pest effects into models can be useful to couple field-level observations of pest effects to the underlying processes, and thus provide understanding. They can be used for yield loss assessment, predicting effects of pests on future yield and providing insight to optimize strategic and tactical decision-making in pest management. When the models are physiologically based and dynamic, pest-crop models allow mimicry of yield loss more realistically than other approaches because the yield loss caused by a given level of injury or disease severity will depend on the time at which it occurs.

Dynamic, physiologically based pest-crop models allow simulation of yield losses in a real-time pest-crop system. They have a great potential not only for adjusting crop simulations for pest stress and thus for arriving at more realistic yield expectations, but also for exploring yield consequences of hypothetical pest-infestation scenarios. The approach has the potential to be applied across pest situations and cropping conditions.

Economic values such as yield goal, price per unit of yield, control costs, benefit-cost ratio, and marginal net return must be taken into consideration in the future. Thresholds can be obtained that indicate when actions to control specific pests are justifiable. Risk analyses will certainly play an important role in the future. Least-loss strategies can thus be developed and pesticide application schemes be optimized. Pest-crop models can then help improve decision-making in IPM, as emphasized by Teng (1988).

Pest-crop models could also be used to generate information from extensive simulation studies in a condensed form. For example, iso-loss curves, least-loss look-up tables, and other means like new approaches for simple models can be produced based on simulation outputs, for assisting in practical decision-making.

\section{CONCLUSIONS}

Before pest-crop models can be widely applied, improving our under- 
standing of the complex system is needed. This requires physiological research as well as field studies to test the models. One essential issue that needs further investigation is the role of active compensation for pest damage in plants. Pest-crop models, like other models, must be validated on field data. To ensure transportability of the approach, the field data should also represent a broad range of conditions. Intensive collaboration by scientists in ICASA* would help bring together the different approaches used thus far, which range from detailed physiological studies on damage mechanisms for model analysis to simple approaches based on literature surveys and 'guesstimates'.

A conclusion can be made that pest-crop modeling has enhanced our understanding of pest effects on crops, and much has been accomplished in developing techniques to couple the effects to crop models for simulating yield loss. The actual use of the coupled models and their outputs for decision support, however, is still lagging behind the progress made in modeling. This aspect of a focus on applications of the models requires more attention as the approach of linking pest and crop models has a great potential for developing improved, knowledge-based pest management systems.

\section{REFERENCES}

Alocilja, E. C. \& Ritchie, J. T. (1988). Upland rice simulation and its use in multicriteria optimization. Research Report Series No. 1, IBSNAT Project, University of Hawaii, Honolulu, HI, p. 95.

Bastiaans, L. (1991). The ratio between virtual and visual lesion size as a measure to describe reduction in leaf photosynthesis of rice due to leaf blast. Phytopatholoy, 81(6), 611-15.

Bastiaans, L. (1993). Understanding yield reduction in rice due to leaf blast. $\mathrm{PhD}$ thesis, Agric. Univ., Wageningen, the Netherlands.

Bastiaans, L. \& Kropff, M. J. (1993). Effects of leaf blast on photosynthesis of rice. 2. Canopy photosynthesis. Neth. J. Plant Path., 99, 205-17.

Benigno, E. A., Shephard, B. M., Rubia, E. G., Arida, G. S., Penning De Vries, F. W. T. \& Bandong, J. P. (1988). Simulation of rice leaffolder population dynamics in lowland rice. IRRI Res. Pap. Ser. No. 135, p. 8.

Boote, K. J., Jones, J. W., Mishoe, J. W. \& Berger, R. D. (1983). Coupling pests to crop growth simulators to predict yield reductions. Phytopatholoy, $\mathbf{7 3}$, $1581-7$.

Boote, K. J., Batchelor, W. D., Jones, J.W., Pinnschmidt, H. \& Bourgeois, G. (1993). Pest damage relations at the field level. In Systems Approaches for Agricultural Development, eds F. W. T. Penning De Vries, P. Teng \& K. Metselaar. Kluwer Academic, Dordrecht, pp. 277-96

*International Consortium for the Application of Systems Approaches in Agriculture. 
Calvero, S. B. \& Teng, P. S. (1992). Validation of BLASTSIM.2 model in IRRI blast (B1) nursery and Cavinti, Laguna, Philippines. International Rice Research Newsletter, 17(5), 20-1.

Cheng, C. H. (1987). Investigation on bioeconomics of the rice leaffolder, Cnaphalo-crocis medinalis (Guenee) in the south of Taiwan. Plant Protection Bulletin, 29, 135-46.

Elings, A. \& Rubia, E. G. (eds). (1994). Analysis of Damage Mechanisms by Pests and Diseases and Their Effects on Rice Yield. SARP Workshop Research Proceedings, Los Banos, Philippines, 18 April-6 May 1994. IRRI, DLO-AB and TPE-LUW, Wageningen, the Netherlands, p.279.

Goudriaan, J. \& Van Roermund, H. W. (1989). Modeling of ageing, development, delays and dispersion. In Simulation and Systems Management in Crop Protection, eds R. Rabbinge, S. A. Ward \& H. H. Van Laar. Simulation Monographs, PUDOC. Wageningen, the Netherlands, pp.47-80

Graf, B., Gutierrez, A. P., Rakotobe, O., Zahner, P. \& Delucchi, Y. (1990a). A simulation model for the dynamics of rice growth and development: Part II - The competition with weeds for nitrogen and light. Agric. Syst. J., 32, 367-92.

Graf, B., Rakotobe, O., Zahner, P.; Delucchi, Y \& Gutierrez, A. P. (1990b). Simulation model for the dynamics of rice growth and development: the carbon balance. Agric. Syst. J., 32, 341-65.

Heong, K. L. (1990). Feeding rates of the rice leaffolder, Cnaphalocrocis medinalis (Lepideoptera: Pyralidae) on different plant stages. J. Appl. Entomology, 7, 81-90.

Jones, J. W. (1993). Decision support systems for agricultural development. In Systems Approaches for Agricultural Development, eds F. W. T. Penning de Vries, P. Teng \& K. Metselaar. Kluwer Academic, Dordrecht, pp. 459-71.

Jones, J. W., Boote, K. J., Jagtap, S. S., Hoogenboom, G. \& Wilkerson, G. G. (1989). SOYGRO V5.41: Soybean Crop Growth Simulation Model User's Guide. Agric. Engr. Dept., Univ. of Florida, Gainesville, FL.

Kim, J. W. \& Kim, D. H. (1986). Studies on the resistance of rice varieties to biotypes of the brown plant hopper, Nilaparvata lugens STAL. Korean J. Plant Protection, 24(4), 209-17.

Kropff, M. J. (1988). Modeling the effect of weeds on crop production. Weed Res., 28, 465-71.

Kropff, M. J. \& van Laar, H. H. (eds). (1993). Modelling Crop Weed Interactions. CAB International, Wallingford, UK and the International Rice Research Institute, Los Banos, Philippines, p. 274.

Kropff, M. J. \& Spitters, C. J. T. ( 1991). A simple model of crop loss by weed competition from early observations on relative leaf area of the weeds. Weed Res., 31, 97-105.

Kropff, M. J., Vossen, F. J. H., Spitters, C. J. T. \& de Groot, W. (1984) Competition between a maize crop and a natural population of Echinochloa crusgalli (L.). Netherlands J. Agric. Sci., 32, 324-7

Kropff, M. J., Spitters, C. J. T., Schnieders, B. J., Joenje, W. \& de Groot, W. (1992). An ecophysiological model for inter specific competition, applied to the influence of Chenopodium album L. on sugar beet. II. Model evaluation. Weed Res., 32, 451-63. 
Kropff, M. J., van Laar, H. H. \& Matthews, R. B. (eds) (1994). ORYZA1: a Basic Model for Irrigated Lowland Rice Production. International Rice Research Institute, Los Banos, Philippines. p. 89.

Loomis, R. S. \& Adams, S. S. (1983). Integrative analysis of host-pathogen relations. Ann. Rev. Phytopath., 21, 341-62.

Luo, Y., Teng, P. S., Fabellar, N. G. \& TeBeest, D. O. (1995). Simulation of rice blast epidemics under global change in several Asian countries, in review.

Penning de Vries, F. W. T., Jansen, D. M., ten Berge, H. F. M. \& Bakema, A. (1989). Simulation of Ecophysiological Processes of Growth in Several Annual Crops. Simulation Monographs, PUDOC, Wageningen, the Netherlands and International Rice Research Institute, Los Banos, Philippines, p. 271

Pinnschmidt, H. O., Batchelor, W. D. \& Teng, P. S. (1994). Simulation of multiple species pest damage on rice. Agric. Syst., 48, 193-222.

Rabbinge, R. (1983). How to use combination models in crop protection. SROP, WPRS Bull., IOBC, pp. 31-45.

Rabbinge, R. \& Bastiaans, L. (1989). Combination models, crop growth and pests and diseases. In Simulation and Systems Management in Crop Protection, eds R. Rabbinge, S. A. Ward \& H. H. Van Laar. PUDOC, Wageningen, 217-39.

Rabbinge, R. \& Carter, N. (1983). Application of simulation methods in the epidemiology of pests and diseases: an introductory review. SROP WPRS Bull., 6(2), 17-30.

Rabbinge, R. \& Rijsdijk, F. H. (1984). Epidemiological and crop physiological basis of EPIPRE. In Cereal Production, ed E. J. Gallagher. Butterworths, London, pp. 227-35.

Rabbinge, R., Ward, S. A. \& Van Laar, H. H. (eds) (1989). Simulation and Systems Management in Crop Protection. Simulation Monographs, PUDOC, Wageningen, the Netherlands, p. 420.

Rabbinge, R., Rossing, W. A. H. \& van der Werf, W. (1993). Systems approaches in epidemiology and plant disease management. Neth. J. Plant Path., 99, Suppl. 3, 161-71.

Rabbinge, R., Rossing, W. A. H. \& van der Werf, W. (1994). Systems approaches in pest management: the role of production ecology. In Proceedings of the Fourth Int. Conf. on Plant Protection in the Tropics, 28-31 March 1994, Kuala Lumpur, Malaysia, eds A. Rajan \& Y. Ibrahim, pp. 25-46.

Reddy, P. R., Nayak, S. K. \& Bastiaans, L. (1991). Simulation of the effect of bacterial blight disease on crop growth and yield of rice. In Simulation and Systems Analysis for Rice Production (SARP), eds F. W. T. Penning De Vries, H. H. Van Laar \& M. J. Kropff. PUDOC, Wageningen, the Netherlands pp. 340-7.

Rijsdijk, F. H., Zadoks, J. C. \& Rabbinge, R. (1989). Decision making and data management. In Simulation and Systems Management in Crop Protection, eds R. Rabbinge, S. A. Ward \& H. H. Van Laar. Simulation Monographs, PUDOC, Wageningen, the Netherlands, pp. 265-77.

Rossing, W. A. H. (1993). On damage, uncertainty and risk in supervised control. PhD thesis, Agric. Univ., Wageningen, the Netherlands.

Rouse, D. I. (1988). Use of crop growth-models to predict the effects of disease. Ann. Rev. Phytopath, 26, 183-201.

Rubia, E. G. \& Penning De Vries, F. W. T. (1990). Simulation of yield reduction caused by stemborers in rice. J. Plant Protec. Tropics, 7(2), 87-102. 
Singh, R. A. \& Das, B. (1991). Simulation of yield loss due to sheath blight in rice crops. In Simulation and Systems Analysis for Rice Production (SARP), eds F. W. T. Penning De Vries, H. H. Van Laar \& M. J. Kropff. PUDOC, Wageningen, the Netherlands pp. 348-52.

Singh, U., Ritchie, J. T. \& Godwin, D. C. (1993). A User's Guide to CERESRice - V2.10. Int. Fert. Dev. Center, Muscle Shoals, AL, p. 132.

Sogawa, K. (1970). Studies on the feeding habits of the brown plant hopper. 2. Honeydew excretion (in Japanese, English summary). J. Entomol. Zool., 14, 134-9.

Spitters, C. J./ (1989). Weeds: population dynamics, germination and competition. In Simulation and Systems Management in Crop Protection, eds R. Rabbinge, S. A. Ward \& H. H. Van Laar. PUDOC, Wageningen, the Netherlands, pp. 182-216.

Spitters, C. J. T. \& Aerts, R. (1983). Simulation of competition for light and water in crop-weed associations. Aspects Appl. Biol., 4, 467-81.

Spitters C. J. T., van Keulen, H. \& van Kraalingen, D. W. G. (1989). A simple and universal crop growth simulator: SUCROS87. In Simulation and Systems Management in Crop Protection, eds R. Rabbinge, S. A. Ward, \& H. H. Van Laar. Simulation Monographs. PUDOC, Wageningen, the Netherlands, pp. 147-81.

Teng, P. S. (1985). A comparison of simulation approaches to epidemic modeling. Ann. Rev. Phytopathol., 23, 351-79.

Teng, P. S. (1988). Pests and pest-loss models. Agrotechnology Transfer, 8(1), $5-10$.

Teng, P. S. (1994). Integrated pest management in rice. Expl. Agricu., 30, $115-37$.

Teng, P. S. \& Johnson, K. B. (1988). Analysis of epidemiological components in yield loss assessment. In Experimental Techniques in Plant Disease Epidemiology, eds J. Kranz \& J. Rotem. Springer-Verlag. New York, pp. 179-90.

Teng, P. S. \& Rouse, D. I. (1984). Understanding computers - applications in plant pathology. Plant Disease, 68, 539-43.

Teng, P. S. \& Savary, S. (1992). Implementing the systems approach in pest management. Agric. Syst. J., 40, 237-64.

Teng, P. S., Batchelor, W. D., Pinnschmidt, H. O. \& Wilkerson, G. (1995a). Simulation of pest effects on crops using coupled pest-crop models: the potential for decision support. In IBSNAT: A Systems Approach to Research and Decision Making, eds G. Tsuji, G. Hoogenboom \& P. K. Thornton, in press.

Teng, P. S., Heong, K. L., Kropff, M. J., Nutter, F. W. \& Sutherst, R. W. (1995b). Linked pest-crop models under global change, (in press).

Weaver, S. E., Kropff, M. J. \& Groeneveld, R. M. W. (1992). Use of ecophysiological models for crop-weed interference: The critical period of weed interference. Weed Sci., 40, 302-7.

Wilkerson, G. G., Jones, J. W., Coble, H. D. \& Gunsolus, J. L. (1990). SOYWEED: a simulation model of soybean and common cocklebur growth and competition. Agron. J., 82, 1003-10.

Zadoks, J. C. (1985). On the conceptual basis of crop loss assessment: the threshold theory. Ann. Rev. Phytopathol., 23, 455-73. 